\title{
Intrinsic Factors Contributing to Axon Regeneration in the Mammalian Nervous System
}

\author{
Ferdinando Rossi
}

\section{1}

\section{Introduction}

The success or failure of neural circuit rewiring through axon regeneration depends on the interplay between two main determinants. The injured neurons must synthesize structural components for outgrowing processes and activate signal transduction pathways to sense and decode guidance cues. At the same time, the surrounding microenvironment must provide suitable substrates and information to promote and direct axon elongation. Although there is general agreement that both neuronal and environmental factors are responsible for the poor outcome of brain repair, over the past decades attention has been mainly focused on the latter aspect. In particular, the observation that adult central nervous system (CNS) neurites can elongate into the growth-permissive peripheral nervous system (PNS) environment (Bray and Aguayo, 1989), together with the discovery that myelinating oligodendrocytes express neurite growth-inhibitory proteins (Schwab et al., 1993), have led to the notion that central neurons may be capable of regrowing their axons, but they fail because of adverse environmental conditions. Accordingly, in recent years an expanding set of growth-inhibitory molecules and related signaling pathways have been described in the CNS milieu (e.g., Fawcett and Asher, 1999; Filbin, 2003; Schwab, 2004; Silver and Miller, 2004). Nevertheless, numerous observations indicate that the intrinsic properties of the affected neurons are also crucial to determine the result of repair processes.

Different types of nerve cells, when confronted with the same environment, show remarkably variable regenerative capabilities, from growth cone formation in vitro (Chierzi et al., 2005; Verma et al., 2005) to axon regeneration in vivo (Benfey et al., 1985; Rossi et al., 1995; Bravin et al., 1997). The strength of regenerative phenomena is tightly related to the activity of a set of neuronal genes associated with growth cone function and process elongation (Fawcett, 2001; Fawcett et al., 2001; Fernandes and Tetzlaff, 2001). The ability for up-regulating such genes in response to injury is not equal among central neurons (Herdegen et al., 1993; Schaden et al., 1994; Vaudano et al., 1995; Buffo et al., 1998, 2003; Zagrebelsky et al., 
1998), and declines considerably with age (Chen et al., 1995; Li et al., 1995; Dusart et al., 1997; Gianola and Rossi, 2001). As a consequence, the neutralization of major inhibitory cues may result scarcely effective, if not accompanied by the activation of intrinsic neuritic growth mechanisms (Fischer et al., 2004a,b).

These observations indicate that removal of extrinsic inhibition may be important, but it is not sufficient to achieve CNS repair. On the other hand, it is also clear that in adult neurons the molecular machinery required to sustain neuritic growth is not constitutively active, but it is subject to strict control mechanisms, the nature and biological meaning of which are still unclear. In this chapter, current knowledge about the role of intrinsic factors in axon regeneration will be reviewed, and the main mechanisms that regulate their expression and function described. Finally, the physiological significance of neuritic growth control in the intact or injured CNS will be discussed.

\section{2}

\section{Modes of Axon Growth}

Axon growth includes several different processes, ranging from elongation of the axon stem to structural remodeling of terminal arbors (Fig. 2.1). Two principal modes of axon growth have been defined as elongating and arborising (Smith and Skene, 1997). Elongating refers to long-distance outgrowth of the axon stem towards its postsynaptic partners. This requires the expression of a specific set of genes (see above), and involves a characteristic cell structure, the growth cone, the function of which is to sense guidance cues and steer neurite navigation. Arborizing growth initiates as soon as the axon reaches its target region and develops terminal ramifications and synaptic contacts. Coincidentally, the molecular machinery associated with synaptic transmission is up-regulated (Hökfelt et al., 1994), whereas growth molecules are turned off or confined to terminal branches (Skene, 1989, 1992; Kapfhammer and Schwab, 1994a). Arborizing growth persists in adult intact neurons to sustain structural plasticity and synaptic turnover (Purves et al., 1987).

Following injury in the adult, the affected neurons must resume the elongating mode in order to form a new growth cone and regenerate the severed axon stump. Such a switch of growth status, which occurs spontaneously only in some axotomized neurons, is not a faithful recapitulation of developmental processes, because it involves specific regulatory mechanisms (Liu and Snider, 2001; Udvadia et al., 2001) and effector molecules (Bates and Meyer, 1997; Bonilla et al., 2002). In addition, another major difference between regeneration and developmental neuritogenesis is that the latter is not exclusively accomplished through growth conedriven elongation of the axon stem: most projection pathways are formed well before the end of development and, therefore, axons that already reached their targets must elongate further to match the progressive expansion of the nervous system or of the whole body. Such interstitial neuritic growth, which is usually overlooked, is responsible for most of the final neuritic length and progresses at extremely fast rates (Pfister et al., 2004). This type of elongation does not contrib- 


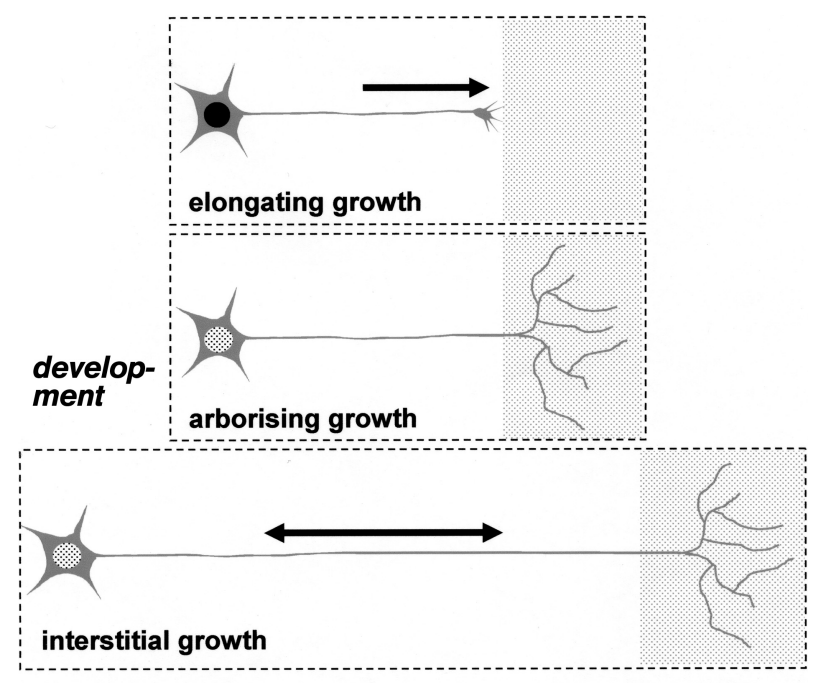

\section{adult}

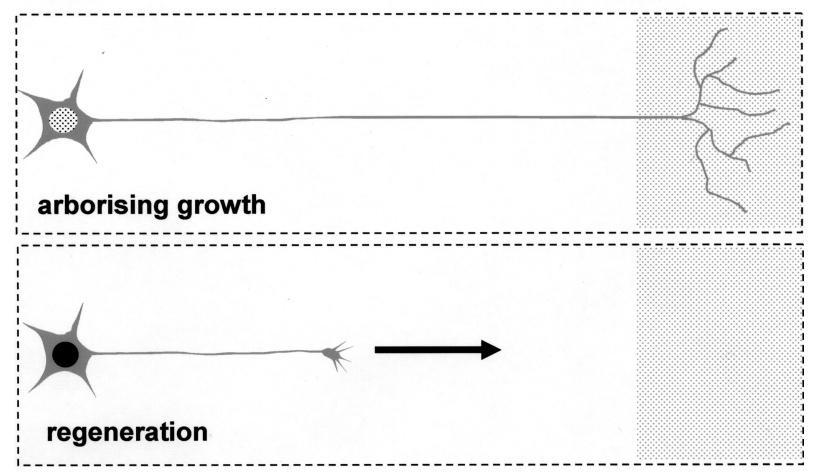

Fig. 2.1. Modes of axon growth. During development, neuritogenesis is first accomplished through elongation of the axon stem driven by the growth cone, and sustained by a specific set of growth-associated genes (elongating growth). As soon as the axon reaches its target region (indicated by the shading), the growth pattern changes to develop the terminal arbor and synaptic contacts (arborizing growth). Elongation of the neuritic stem continues throughout development to match the concomitant growth of the whole organism (interstitial growth). Arborizing growth persists in the adult to sustain structural plasticity and synaptic turnover. Following axotomy, injured axons must resume the elongating growth mode in order to regenerate their axons. Note, however, that in this case growth conedriven elongation has to restore the entire neuritic length.

ute significantly to regeneration in the adult. However, this implies that the entire axonal length must be restored by growth cone-driven outgrowth. If the neuron's ability to maintain such a mechanism is limited in space or time (Davies, 1994), the maximum extent of axon regeneration may be seriously restricted. 
It must be emphasized that the two main modes of growth depicted above do not represent all-or-none alternative conditions, but rather the extreme ends of a continuum that can be finely tuned by regulatory mechanisms. As a consequence, depending on their age, phenotype, or other specific circumstances, different types of neurons show peculiar intrinsic properties both in their basal growth competence and in their potential to regenerate after injury. In the latter instance, however, both modes of growth can be relevant. The elongating mode is required to regenerate severed axons, whereas the arborizing mode sustains collateral reinnervation and compensatory reorganization, which are often most important for functional recovery (Raisman and Field, 1973; Murray and Goldberger, 1974; Pons et al., 1991; Rossi et al., 1991; Raineteau and Schwab, 2001; Bareyre et al., 2004).

\section{3}

\section{Developmental Regulation of the Intrinsic Neuronal Growth Properties}

The ability to activate growth genes and form growth cone-like structures substantially declines as neurons mature (Fawcett, 2001; Fernandez and Tetzlaff, 2001). At the same time, the ability for sustaining extensive structural remodeling, which is characteristic of the juvenile brain, is also considerably reduced (Purves and Lichtman, 1985). Therefore, some major events occurring during development modify the neuron competence for axon growth and plasticity and greatly restrict its regenerative potential. As for many biological processes, regulation of neuronal growth is not mediated by a single mechanism, but by the concurrent action of multiple factors. Such factors include both positive (i.e., growth-promoting) and negative (i.e., growth-inhibitory) stimuli, the balance of which determines the actual growth ability of the neuron. Nevertheless, because of our interest in the mechanisms that limit neuronal growth properties at the end of development, attention here will mainly be focused on negative signals.

\subsection{1}

\section{Purely Intrinsic Mechanisms}

Although it is difficult to define a purely intrinsic mechanism in cells that live in a complex social environment, there is some evidence that the neuronal growth potential can be regulated in a cell-autonomous manner. In distinct types of sensory and autonomic neurons the rate of axonal growth and the duration of neurotrophin independence in vitro are different and related to the distance from their natural target fields in vivo (Davies, 1994). This suggests that the different phases of neuronal maturation follow a precise time-schedule regulated by an inner clock, set so as to meet the specific ontogenetic requirements of each neuron population. Although it has been shown that other neurons, such as retinal ganglion cells, are not able to modify their growth potential in a cell-autonomous manner (Goldberg et al., 2002), such a mechanism could seriously affect axon regeneration in the 
adult, when the duration of growth processes or the distances to be covered are longer than during development.

\subsection{2}

\section{Target-Derived Factors}

A most obvious external source of regulatory cues for outgrowing axons is represented by their target cells. Molecules released by postsynaptic partners, and retrogradely transported to the cell body, signal to the afferent neuron that its axon has reached the proper terminal field and induce the switch to the arborizing growth mode. Following axotomy, disconnection from target cells - together with the action of injury-associated growth-promoting cues (see below) - triggers the reactivation of elongating neuritic growth, which is again suppressed when regeneration is accomplished (Fawcett et al., 2001; Fernandes and Tetzlaff, 2001).

This mechanism is particularly important in the PNS (Baizer and Fishman, 1987; Skene, 1989, 1992). In adult peripheral neurons, growth-associated genes (e.g., GAP-43) can be up-regulated in response to target loss (Verzé et al., 1996) or blockade of axonal transport (Woolf et al., 1990; Wu et al., 1993). In addition, the cellular/molecular changes induced by axotomy are typically reversed when the severed axons rejoin their terminal fields, but they are maintained for long periods if regeneration is prevented (Bisby, 1988; Woolf et al., 1990; Schreyer and Skene, 1991; Fernandes and Tetzlaff, 2001). The identity of such target-derived cues, as well as their mechanisms of action, have still to be elucidated. Candidate molecules include neurotrophins (Fernandes et al., 1998; Mohiuddin et al., 1999) and growth factors (Blottner and Herdegen, 1998), the application of which attenuates the cell body response of axotomized neurons (see Rossi, 2004). Retrograde signals may also contribute to regulate neuritic growth in the CNS. The expression of neuronal growth-associated proteins can be influenced by target-derived cues in both developing (Karimi-Abdolrazee and Schreyer, 2002) and adult neurons (Hughes et al., 1997; Bormann et al., 1998; Haas et al., 1998). Furthermore, the same proteins can be up-regulated following the loss of postsynaptic partners (Buffo et al., 2003) or the blockade of axonal transport (Leah et al., 1993; Zagrebelsky et al., 1998; Buffo et al., 2003). These effects, however, are not consistent among different neuron phenotypes, and it is often difficult to distinguish the effect of target influences from that of other extrinsic cues.

\subsection{3}

\section{Factors Acting Along the Axon}

In the CNS, the strength of the cellular response to axotomy, and the success of the ensuing regeneration, are also dependent on lesion conditions and, namely, on the distance of the transection site from the cell body. For instance, retinal ganglion cells (Doster et al., 1991; Hüll and Bähr, 1994), rubrospinal (Tetzlaff et al., 1994; Fernandes et al., 1999) or corticospinal neurons (Mason et al., 2003) up-regulate 
growth-associated genes and regenerate into peripheral nerve implants only when their axons are severed in the vicinity of the perikaryon. Therefore, it has been proposed that in the CNS regulation of neuronal growth properties is also mediated by negative signals issued along the axon: only a proximal injury would remove a sufficient amount of such signals to release the neuron from inhibitory control (Skene, 1989, 1992). It is the sources and nature of these cues that are unknown. Retinal ganglion cells do not respond to an intracranial optic nerve transection, but they react to an intraorbital transection, irrespective of their position relative to the optic disk. This indicates that the crucial condition is not the actual distance of axon injury from the cell body, but, rather, the length of the remaining myelinated axon segment along the optic nerve (Doster et al., 1991; Meyer et al., 1994). As a consequence, oligodendrocytes, and/or associated molecules, are likely candidates to exert this regulatory function.

During development, myelinogenesis and the appearance of myelin-associated inhibitory proteins are coincident with the down-regulation and redistribution of neuronal growth proteins (Kapfhammer and Schwab, 1994a,b). Therefore, in addition to their established growth cone- collapsing activity (Filbin, 2003; Schwab, 2004), myelin-associated proteins may also regulate the intrinsic growth properties of adult neurons. In the adult CNS, functional neutralization of the myelinassociated protein Nogo-A induces the expression of some growth-associated genes in Purkinje cells (Zagrebelsky et al., 1998) and spinal cord neurons (Bareyre et al., 2002). Although this treatment also induces robust neuritic growth (Buffo et al., 2000; Bareyre et al., 2002), it does not improve the regenerative abilities of refractory neurons such as Purkinje cells. In addition, myelin ablation does not prevent the developmental decline of Purkinje cell regenerative capabilities (BouslamaOueghlani et al., 2003; Dusart et al., 2005). Together, these observations indicate that myelin-associated molecules exert a strong action on local neuritic plasticity, but their effect on the expression of growth genes is milder and might require extensive demyelination (Hiebert et al., 2000). However, it is likely that growth regulation is mediated by different concurrent cues, including multiple molecular signals acting along the axon. As a consequence, procedures that interfere with single factors necessarily produce minor effects.

\subsection{4}

\section{Factors Acting on the Cell Body}

Although major efforts in the study of the factors controlling neuronal growth properties have been directed at investigating retrograde cues acting on the axon, there is evidence that signals present in the cell body microenvironment may be also important. For instance, the response to injury and regenerative potential of adult neurons can be boosted by neurotrophins (Kobayashi et al., 1997; Kwon et al., 2002) or cAMP (Neumann et al., 2002; Qiu et al., 2002) directly applied to the perikaryon, indicating that regulatory cues (positive ones in this case) may not need to act through the axon. In addition, it has been recently shown that the de- 
velopmental loss of growth potential in retinal ganglion cells can be induced by signals issued by neighboring amacrine neurons (Goldberg et al., 2002). Retinal ganglion cells placed in vitro at different embryonic or postnatal ages show a dramatic decrease of neuritic extension around the day of birth. This effect is not due to intrinsic maturation of the neuron, since embryonic cells retain the same growth pattern even after long times in culture. In contrast, a striking loss of growth ability occurs when the same cells are plated together with amacrine neurons. Since this decline of axon growth is coincident with an increase of dendritic extension, it has been proposed that local signals induce a switch of growth competence in the retinal ganglion cell from axonogenesis to dendritogenesis. Although this remains the most compelling example of such a mechanism, there is correlative evidence that it may also operate on other neurons. For instance, the decline of regenerative capacity of cerebellar Purkinje cells in vivo (Gianola and Rossi, 2001) correlates with the late phase of dendritogenesis when these neurons engage in extensive synaptogenesis with parallel fibers (Armengol and Sotelo, 1991; Dusart et al., 2005).

These observations indicate that multiple concurrent factors contribute to regulate the expression of neurite growth genes and restrict the reparative potential of maturing neurons. Regeneration in the adult depends on the ability for reversing this condition. This appears to be feasible in peripheral neurons, but much more difficult in their central counterparts. Although the latter neurons may be subjected to more complex and strict regulatory mechanisms, another important issue refers to the actual reversibility of the cellular changes that take place at the end of development. It is possible that, in order to accomplish their specific functional role, some neuron phenotypes have permanently to suppress certain cellular processes, such as those related to neuritic elongation. If this is the case, then removal of environmental inhibitory molecules may facilitate the expression of constitutive potentialities, but this would fail to trigger a full regenerative response. To date there is little evidence that maturing neurons undergo irreversible modifications in their neuritic growth competence (see Goldberg et al., 2002). However, the frequent observation that only a minor fraction of injured neurons succeed in regenerating into a growth-permissive environment (Dusart et al., 2005) indicates that most of the currently available procedures are not adequate to stimulate large neuronal populations.

\section{4}

Injury-Derived Regulation of Intrinsic Neuronal Growth Properties

Although major changes of neuronal growth properties occur during normal development, additional signals that influence regenerative processes are produced by injury itself. Indeed, tissue damage induces profound modifications of the CNS environment with the appearance of novel positive or negative stimuli. 
2.4.1

\section{Negative Regulation by Injury-Associated Factors}

It is well established that a major obstacle for axon regeneration following CNS injuries is the presence of inhibitory molecules in glial scars (see Fawcett and Asher, 1999; Silver and Miller 2004 for comprehensive reviews on this subject). In addition, recent reports have suggested that some normally expressed molecules, such as myelin-associated proteins, are also enriched in injury sites (Schwab et al., 2005). All of these factors hamper regeneration by arresting the progression of growth cones, but it is not clear whether they also affect the expression of neuronal growth genes. The only indication that scar components may also dampen the cellular response to injury comes from the observation that enzymatic degradation of chondroitin sulfate proteoglycans (CSPGs) in the injured spinal cord induces upregulation of GAP-43 in dorsal root ganglion neurons (Bradbury et al., 2002).

\subsection{2}

\section{Positive Regulation by Injury-Associated Factors}

In addition to growth-inhibitory factors, substances endowed with neuroprotective or growth-promoting activity may be also produced by cells participating in the tissue response to injury, including glial cells (Shadiack et al., 1998) or elements of the immune system (Hauben and Schwartz, 2003; Schwartz, 2004). The effect of these molecules on the activation of neuronal growth genes is limited and generally overwhelmed by that exerted by negative signals. However, they might ultimately prove to be most useful for the development of novel therapeutic strategies (e.g., Hauben and Schwartz, 2003).

Another important mechanism concerns positive signals issued from the injured neurite itself to inform the cell body about the lesion event and elicit its compensatory response (Perlson et al., 2004). Axotomy triggers a burst of antidromic electrical activity, which may convey a fast retrograde signal to the perikaryon (Berdan et al., 1993). Indeed, blockade of electrical activity delays regeneration of cortical neurons axotomized in vitro (Mandolesi et al., 2004), while electrical stimulation of injured motor neurons in vivo induces up-regulation of growth genes and potentiates neuritic elongation (Al-Majed et al., 2004). The same procedure is ineffective on rubrospinal neurons, again underscoring differences between central and peripheral nerve cells (Harvey et al., 2005). However, the relative contribution of synaptic activation and antidromic stimulation in these phenomena remains the subject of debate (see Harvey et al., 2005).

In addition to electrical activity, axotomy may also stimulate the production of positive chemical cues. Upon neuritic injury, a number of proteins, among which are included importin $\beta$ and vimentin, are synthesized through local translation of intra-axonal mRNAs (Hanz et al., 2003; Perlson et al., 2005). These proteins interact to form macromolecular complexes that shuttle signaling molecules, such as activated kinases, to the perikaryon and the nucleus (Blesch and Tuszynski, 2004; Hanz and Fainzilber, 2004). Together with the loss of target-derived inhibitory cues 
(see above), this mechanism has been shown to modulate the cell body response to injury in peripheral neurons (Hanz et al., 2003; Perlson et al., 2005). However, its relevance in the CNS has still to be defined.

\section{5}

\section{Procedures to Enhance Intrinsic Growth Potential}

During the past few years several different strategies have been developed and tested to promote axonal regeneration by enhancing intrinsic growth properties of adult neurons. In particular, three main approaches have been followed, including conditioning lesions, pharmacological stimulation of the cell body response, and overexpression of neuronal growth genes.

\subsection{1}

\section{Conditioning Lesions}

This approach was first attempted to improve the regeneration of the central branch of dorsal root ganglion (DRG) neurons. Based on the observation that a lesion of the peripheral axon induces a strong regenerative response, whereas transection of the central one does not (Schreyer and Skene, 1993), it has been proposed that the cell body changes triggered by a peripheral injury could also sustain the regeneration of the central neurite. Indeed, adult DRG neurons, when dissociated and transplanted to the adult CNS, vigorously elongate their axons into white matter tracts (Davies et al., 1997, 1999). In addition, in the presence of a peripheral injury, central DRG axons are able to regenerate into a peripheral nerve implant (Richardson and Issa, 1984) and even across the spinal cord lesion site and into the dorsal funiculus (Neumann and Woolf, 1999). The timing of the priming lesion is crucial: maximal effect is obtained when peripheral axotomy is made one week before that of the dorsal funiculus, whereas no effect is observed when the central injury precedes the peripheral one (Neumann and Woolf, 1999). More recently, it has been shown that a strong growth-promoting effect can be also obtained by two subsequent peripheral lesions, carried out simultaneously to spinal cord injury and one week later (Neumann et al., 2005). As an alternative procedure, induction of growth genes, and concomitant improvement of regeneration, has been obtained in DRG cells by application of cAMP to the cell body (Neumann et al., 2002; Qiu et al., 2002). Also in this case the treatment is only effective before the spinal cord lesion.

Another interesting example comes from the visual system. The implantation of a peripheral nerve segment into the vitreous body improves axon regeneration following optic nerve crush (Berry et al., 1996). This effect has been attributed to trophic factors released by the PNS tissue, which stimulate the growth properties of axotomized retinal ganglion cells. More recently, however, it has been shown that lens injury favors survival of retinal ganglion cells after axotomy and enhances re- 
generation along the optic nerve (Fischer et al., 2000; Leon et al., 2000). This effect is accompanied by strong up-regulation of growth-associated genes (Fischer et al., 2004a), which is induced by the interaction of positive signals derived from both the injured lens tissue and recruited macrophages (Li et al., 2003; Yin et al., 2003; Lorber et al., 2005). Although such priming lesion procedures are not likely to become clinically relevant, they nonetheless represent most suitable experimental models to investigate the interaction between neurons with strong regenerative potentialities and the adult CNS environment.

\section{5 .2}

\section{Pharmacological Stimulation}

In addition to the above-mentioned effect of neurotrophins or cAMP directly applied to the neuronal perikaryon, other substances may be effective in increasing intrinsic regenerative capabilities. Application of the purine nucleoside inosine to goldfish neurons potentiates the expression of axonal growth genes and process outgrowth in vitro (Benowitz et al., 1998; Petrausch et al., 2000). Administration of this molecule to adult rats following unilateral corticospinal tract injury (Benowitz et al., 1999) or cortical ischemia (Chen et al., 2002) stimulates vigorous compensatory sprouting of intact axons, accompanied by some functional recovery. To date, it is still unclear whether inosine may also promote regeneration of injured neurites. Improved regeneration, together with up-regulation of GAP-43, has been also obtained by administration of the immunosuppressant drug tacrolimus (FK-506), both in peripheral (Gold et al., 1995, 1998) and in central neurons (Masden et al., 1998).

\section{5 .3}

\section{Overexpression of Neuronal Growth Genes}

Growth-associated genes can be stably overexpressed in transgenic animals or by virus-mediated gene transfer. Potentiation of neuritic growth capabilities has been obtained in vitro by inducing expression of different integrins (Condic, 2001) or the small proline-rich repeat protein 1A (Bonilla et al., 2002). Overexpression of major growth cone proteins, such as GAP-43 or CAP-23, in transgenic mice induces spontaneous sprouting in different populations of PNS and CNS neurons, and promotes collateral reinnervation at the neuromuscular junction (Aigner et al., 1995; Caroni et al., 1997). When the GAP-43 gene is specifically targeted to Purkinje cells, which are peculiar for their poor regenerative potential (Rossi et al., 1995; Dusart et al., 1997; Carulli et al., 2004), injured axons vigorously sprout into the growthinhibitory white matter environment (Buffo et al., 1997; Gianola and Rossi, 2004). Sprouting, but not regeneration, has been also reported for GAP-43 overexpressing thalamic neurons (Mason et al., 2000), indicating that up-regulation of individual genes may enhance axon plasticity, but it is not sufficient to sustain long-distance neuritic elongation. Accordingly, some regeneration of cut axons into peripheral nerve implants has been observed in double-transgenic mice with GAP-43/CAP- 
23 overexpressing DRG neurons (Bomze et al., 2001) or GAP-43/L1 overexpressing Purkinje cells (Zhang et al., 2005).

\section{6}

\section{How Does Up-Regulation of Neuronal Growth Genes Override Environmental Inhibition?}

Numerous observations reviewed in the previous sections show that induction of growth genes allows at least some axon regeneration, even in the presence of prohibitive environmental conditions. Surprisingly, however, little is known about the cellular/molecular interactions that enable neurons with enhanced growth potentialities to overcome inhibitory influences. Two alternative possibilities may be envisaged (Fig. 2.2). First, activation of growth genes may simply shift the balance between positive and negative mechanisms, allowing process outgrowth regardless of active inhibitory cues. Alternatively, up-regulation of such genes may directly influence negative signal transduction pathways, reducing neuronal sensitivity to extrinsic inhibition.

The combination of lens injury, to stimulate intrinsic mechanisms, with procedures that disrupt environmental negative signals shows that counteracting inhibition alone has little effect without concomitant activation of the neuronal growth programs (Fischer et al., 2004a). In contrast, a remarkable synergistic effect is observed when the two procedures are coupled (Fischer et al., 2004b). This implies that activation of the elongating growth mode may be necessary for long-distance regeneration, but it is not sufficient to completely abolish the effect of extrinsic cues. In line with this conclusion, components of the inhibitory signaling pathways, such as the Nogo receptor or RhoA, are not down-regulated in lens injuryactivated retinal ganglion cells (Fischer et al., 2004b). Therefore, neuronal growth genes do not appear to exert their regeneration-promoting activity by reducing the efficiency of inhibitory signaling pathways.

Nevertheless, another possibility should not be disregarded. In adult intact neurons, growth proteins such as GAP-43 are usually enriched in terminal branches, whereas they are not present along the myelinated neuritic stem (Kapfhammer and Schwab, 1994a). Such a precise distribution is disrupted following demyelinating procedures, suggesting that myelin-derived signals regulate the targeting of growth-associated molecules to unmyelinated axonal domains, which retain the ability for structural remodeling (Kapfhammer and Schwab, 1994b). Interestingly, in transgenic Purkinje cells that overexpress GAP-43, axonal sprouts bud from axon segments which are normally myelinated. Namely, process outgrowth occurs at sites where the growth protein accumulates and the myelin sheath retracts (Gianola and Rossi, 2004). These observations suggest a reciprocal interaction between neuronal growth molecules and myelin-derived cues. Under normal conditions, oligodendroglial factors target these molecules to terminal branches to prevent unwanted growth along the axon. However, if GAP-43 is overexpressed it may accumulate along the neurite and locally disrupt the normal axon-oligodendrocyte rela- 


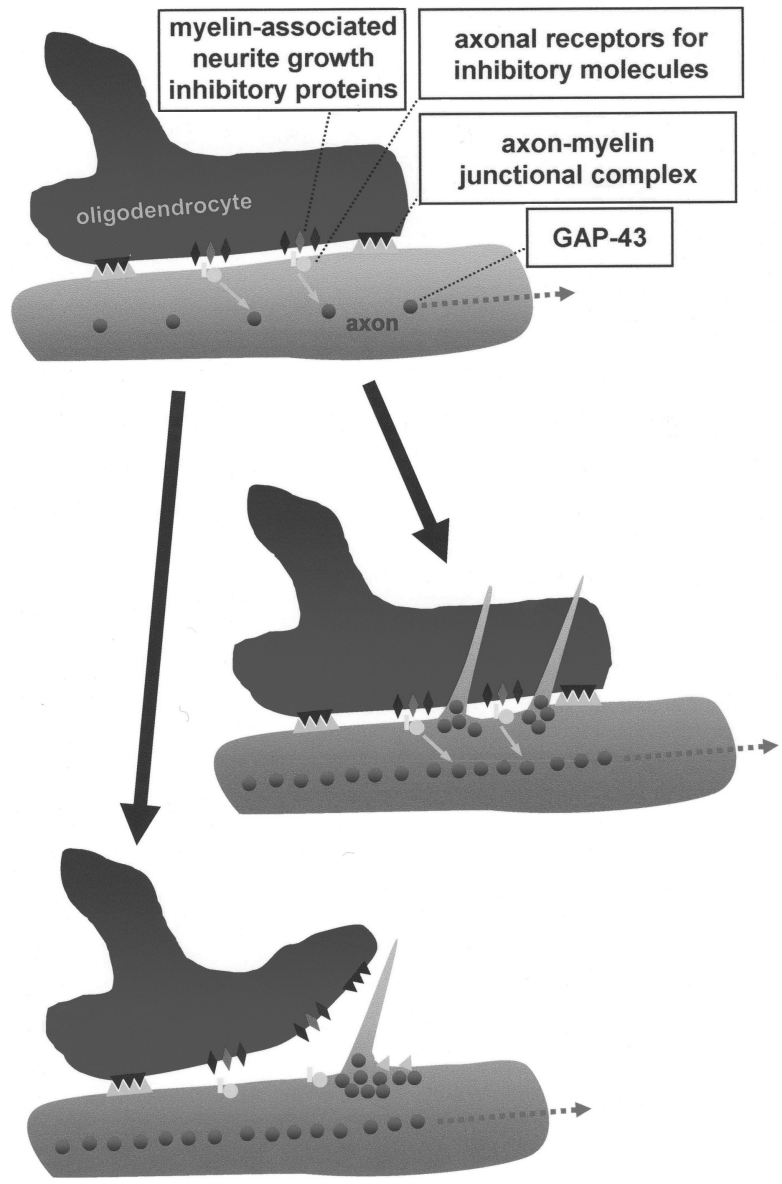

Fig. 2.2. Hypothetical interaction between myelin-associated inhibitory signaling and intrinsic neuronal growth molecules. In the adult intact CNS (upper panel), oligodendrocyte-derived inhibitory signaling hampers axon outgrowth and targets growth proteins, such as GAP-43, towards unmyelinated terminal branches. In the case of overexpression or up-regulation of growth-associated molecules, two possible mechanisms may enable the axon to override extrinsic inhibition. Accumulation of growth proteins may induce process outgrowth simply by shifting the balance between negative and positive mechanisms in favor of the latter ones (center panel). Alternatively (lower panel), GAP-43 may disrupt the normal axonmyelin interaction (junctional complexes) and induce retraction of the oligodendrocyte. In this way, the efficiency of myelin-derived inhibitory signaling is reduced and neuritic sprouting facilitated.

tionship, thus reducing exposure of the neuron to inhibitory influences. In this way, up-regulation of neuronal growth molecules would induce myelin retraction, diminish the effect of inhibitory signaling and, hence, facilitate neuritic sprouting (Gianola and Rossi, 2004). 
2.7

\section{Growth Control and Experience-Dependent Plasticity in the CNS}

A salient feature of adult CNS neurons is the extreme variability in the basal expression of growth genes and in the cellular response to injury that, in turn, determine the particular regenerative capabilities shown by distinct neuronal phenotypes (Lieberman, 1971; Barron, 1989; Herdegen et al., 1997; Carulli et al., 2004). These differences are likely related to the specific functional tasks carried out by each neuron set or subset. A typical example in this context is represented by the inferior olive, where different neuron clusters, which correspond to functional units in the cerebellar cortical network, show remarkable differences in the constitutive expression of growth genes and in the cell body response to axotomy (Buffo et al., 1998, 2003). In other words, cell type-specific regulation of neuronal growth properties is likely required for correct functioning of the nervous system. As a consequence, the intrinsic neuronal abilities for setting up a regenerative response depend on control mechanisms, the ultimate purpose of which is not to hamper regeneration, but to regulate physiological growth (Raisman, 2004; Rossi, 2004).

Most growth-inhibitory molecules, including myelin-associated proteins and components of the extracellular matrix, such as CSPGs, are constitutively expressed in the adult intact CNS and are strategically positioned to regulate structural remodeling. Their appearance at the end of development is correlated with the closure of critical periods for experience-dependent plasticity (Haug et al., 1976; Lander et al., 1997; Schoop et al., 1997). Procedures that interfere with myelin formation or signaling during development induce abnormal neuritic patterns in different CNS regions (Schwab and Schnell, 1991; Gianola et al., 2003). In the adult, functional neutralization of myelin-associated proteins (Buffo et al., 2000; Bareyre et al., 2002), or removal of CSPGs (Corvetti and Rossi, 2005) induce aberrant axonal sprouting, in which newly formed processes invade unusual territories. In addition, enzymatic digestion of CSPGs (Pizzorusso et al., 2002) or disruption of myelin-derived inhibitory signaling (McGee et al., 2005) prolong or reactivate the developmentally regulated ocular dominance plasticity in the mature visual cortex. Finally, transgenic mice that overexpress GAP-43, and hence override extrinsic inhibition, show abnormal outgrowth of hippocampal mossy fibers, which is correlated with the occurrence of spontaneous epilepsy (Aigner et al., 1995). Together, these observations indicate that finely tuned growth control mechanisms are turned on at the end of development to secure the specificity of neuronal connections, while allowing a certain degree of plasticity. Procedures or manipulations that shift the balance in favor of growth-promoting mechanisms may result in the formation of aberrant synaptic contacts and functional defects. As a consequence, strict regulation on neuritic growth would be necessary during both physiological plasticity and repair processes after injury to prevent a progressive disorganization of the normal connection patterns.

A number of observations argue against this conclusion. For instance, the aberrant neuritic outgrowth induced by temporary removal of inhibitory molecules in the intact CNS is transitory, and the normal pattern of connectivity is restored 
as soon as regulatory signaling recovers (Buffo et al., 2000; Gianola et al., 2003; Corvetti and Rossi, 2005). Similarly, the spontaneous sprouting of motor nerves in GAP-43 overexpressing mice does not disrupt the normal muscle innervation (Aigner et al., 1995). Therefore, the removal of inhibitory cues, or potentiation of neuronal growth properties, may trigger neuritic plasticity, but it is not sufficient to induce the formation of stable synaptic contacts. On the other hand, there are several examples of reinnervation after injury in which new functional and correctly patterned connections are established (Zagrebelsky et al., 1996, 1997; Thanos et al., 1997; Sauvé et al., 2001; Rossi et al., 2002), and this occurs even when growth-inhibitory cues are suppressed (Thallmair et al., 1998; Z'Graggen et al., 1998; Raineteau and Schwab, 2001). Thus, if proper connections can be maintained or repaired, what is the role of inhibitory mechanisms?

One important factor that must be taken into consideration is that connection patterns in the developing and mature brain are shaped and maintained by experience, that is the interaction of the whole organism (or nervous system) with the surrounding world. Different types of external stimuli can modulate the plastic properties of neural circuits by modifying the expression of neuronal growth proteins (Molteni et al., 2004) or regulatory molecules in the CNS milieu (Lander et al., 1997; Miyata et al., 2004). In addition, specific past experience may profoundly influence the plastic capabilities of adult neural circuits (Knudsen, 1998; Hofer et al., 2006). Therefore, the actual pattern of connectivity that will result from a plastic or repair process will be determined by the reciprocal interaction between intrinsic neuronal growth properties, extrinsic CNS cues and the specific nature of incoming external stimuli. For instance, removal of CSPGs or disruption of the myelinassociated signaling pathway in the adult visual cortex do not lead to significant changes of ocular dominance unless they are associated with monocular deprivation, that is an unusually unbalanced binocular input (Pizzorusso et al., 2002; McGee et al., 2005). In other words, the connections formed (or restored) are always congruent with the actual experience event: a particular interaction with the external world will lead to an appropriate pattern of connectivity. Therefore, growthinhibitory mechanisms are required to prevent highly plastic neural circuits from adapting too easily to irrelevant or abnormal stimuli. At the same time, experiencedependent mechanisms modulate the plastic properties of the nervous system making it responsive to significant events. This emerging concept is most important for both basic and translational research in brain repair. In fact, by the application of targeted external stimuli it may be possible to potentiate the growth/ regenerative properties of injured neurons (e.g., Molteni et al., 2004) and, at the same time, promote the formation of specific connections, capable of restoring adaptive function. Therefore, an efficient regeneration strategy should rely not only on removing molecular mechanisms that restrict axon growth, but also on stimulating appropriate circuit rewiring through targeted rehabilitation paradigms. In this context, it is now crucial to understand how experience-dependent mechanisms can modify the intrinsic neuronal properties for neuritic growth and regeneration. 


\section{Acknowledgments}

These studies were supported by grants from the International Institute for Research in Paraplegia (Zurich, P81/04), the European Community (contract number 512039), and the Ministero dell'Università e della Ricerca Scientifica e Tecnologica (COFIN 2005), University of Turin.

\section{References}

Aigner, L., Arber, S., Kapfhammer, J.P., Laux, T., Schneider, C., Botteri, F., Brenner, H.-R., Caroni, P. Overexpression of the neural growth-associated protein GAP-43 induces nerve sprouting in the adult nervous system of transgenic mice. Cell, 1995, 83, 269-278.

Al-Majed, A.A., Tam, S.L., Gordon, T. Electrical stimulation accelerates and enhances expression of regenerationassociated genes in regenerating rat femoral motoneurons. Cell. Mol. Neurobiol., 2004, 24, 379-402.

Armengol, J.A., Sotelo, C. Early dendritic development of Purkinje cells in the rat cerebellum. A light and electron microscopic study using axonal tracing in in vitro slices. Dev. Brain Res., 1991, 64, 95-114.

Baizer, L., Fishman, M.C. Recognition of specific targets by cultured dorsal root ganglion neurons. J. Neurosci., 1987, 7, 1305-1311.

Bareyre, F.M., Haudenshild, B., Schwab, M.E. Long-lasting sprouting and gene expression changes induced by the monoclonal antibody IN-1 in the adult spinal cord. J. Neurosci., 2002, 22, 7097-7110.

Bareyre, F.M., Kerschensteiner, M., Raineteau, O., Mettenleiter, T.C., Weinmann, O., Schwab, M.E. The injured spinal cord spontaneously forms a new intraspinal circuit in the adult rat. Nat. Neurosci., 2004, 7, 269-277.

BARRon, K.D. Neuronal responses to axotomy: consequences and possibilities for rescue from permanent atrophy or cell death. In Neural Regeneration and Transplantation, Seil, F.J. (Ed.), Alan Liss, New York, 1989, pp. 79-99.
Bates, C.A., Meyer, R.L. The neuritepromoting effect of laminin is mediated by different mechanisms in embryonic and adult regenerating mouse optic axons in vitro. Dev. Biol., 1997, 181, 91-101.

Benfey, M., Bunger, U.R., Vidal-Sanz, M., Bray, G.M., Aguayo, A.J. Axonal regeneration from GABAergic neurons in the adult rat thalamus. J. Neurocytol., 1985, 14, 279-296.

Benowitz, L.I., Jing, Y., TABibiazar, R., Jo, S.A., Petrausch, B., Stuermer, C.A.O., Rosenberg, P.A., Irwin, N. Axon outgrowth is regulated by an intracellular purine-sensitive mechanism in retinal ganglion cells. J. Biol. Chem., 1998, 273, 29626-29634.

Benowitz, L.I., Goldberg, D.E., Madsen, J.R., Soni, D., Irwin, N. Inosine stimulates extensive axon collateral growth in the rat corticospinal tract after injury Proc. Natl. Acad. Sci. USA, 1999, 96, 13486-13490.

BERdan, R.C., EASAW, J.C., Wang, R. Alterations in membrane potential after axotomy at different distances from the soma of an identified neuron and the effect of depolarization on neurite outgrowth and calcium channel expression. J. Neurophysiol., 1993, 69, 151-164.

Berry, M., Carlile, J., Hunter, A. Peripheral nerve explants grafted into the vitreous body of the eye promote the regeneration of retinal ganglion cell axons severed in the optic nerve. J. Neurocytol., 1996, 25, 147-170.

Bisby, M.A. Dependence of GAP-43 (B50, F1) transport on axonal regeneration in rat dorsal root ganglion neurons. Brain Res., 1988, 458, 157-161.

Blesch, A., Tuszynski, M.J. Nucleus hears axon's pain. Nat. Med., 2004, 10, 236-237. 
Blottner, D., Herdegen, T. Neuroprotective Fibroblast Growth Factor type-2 downregulates the c-Jun transcription factor in axotomized sympathetic preganglionic neurons of adult rat. Neuroscience, 1998, 82, 283-292.

Bomze, H.M., Bulsara, K.R., Iskandar, B.J., Caroni, P., Skene, J.H.P. Spinal axon regeneration evoked by replacing two growth cone proteins in adult neurons. Nat. Neurosci., 2001, 4, 38-43.

Bonilla, I.E., Tanabe, K., Strittmatter, S.M. Small proline-rich repeat protein $1 \mathrm{~A}$ is expressed by axotomized neurons and promotes axonal outgrowth. J. Neurosci., 2002, 22, 1303-1315.

Bormann, P., Zumsteg, V.M., Roth, L.W., REINHARD, E. Target contact regulates GAP-43 and alpha-tubulin mRNA levels in regenerating retinal ganglion cells. J. Neurosci. Res., 1998, 52, 405-419.

Bouslama-Oueghlani, L., Wehrlé, R., Sotelo, C., Dusart, I. The developmental loss of the ability of Purkinje cells to regeneratet axons occurs in the absence of myelin: an in vitro model to prevent myelination. J. Neurosci., 2003, 23, 8318-8329.

Bradbury, E.J., Moon, L.D., Popat, R.J., King, V.R., Bennett, G.S., Patel, P.N., Fawcett, J.W., McMahon, S.B. Chondroitinase $\mathrm{ABC}$ promotes functional recovery after spinal cord injury. Nature, 2002, 416, 636-640.

Bravin, M., Savio, T., Strata, P., Rossi, F. Olivocerebellar axon regeneration and target reinnervation following dissociated Schwann cell grafts in surgically injured cerebella of adult rats. Eur. J. Neurosci., 1997, 9, 2634-2649.

Bray, G.M., Aguayo, A.J. Exploring the capacity of CNS neurons to survive injury, regrow axons, and form synapses in adult mammals. In Neural Regeneration and Transplantation, SEIL, F.J. (Ed.), Alan Liss, New York, 1989, pp. 67-78.

Buffo, A., Holtmaat, A.J.D.G., Savio, T., Verbeek, S., Oberdick, J., Oestreicher, A.B., Gispen, W.H., Verhaagen, J., Rossi, F., Strata, P. Targeted overexpression of the neurite growth-associated protein B-50/ GAP-43 in cerebellar Purkinje cells induces sprouting in response to axotomy, but does not allow axon regeneration into growth permissive transplants. J. Neurosci., 1997, 17, 8778-8791.

Buffo, A., Fronte, M., Oestreicher, A.B., Rossi, F. Degenerative phenomena and reactive modifications of the adult rat inferior olivary neurons following axotomy and disconnection from their targets. Neuroscience, 1998, 85, 587-604.

Buffo, A., Zagrebelsky, M., Huber, A.B., Skerra, A., Schwab, M.E., Strata, P., Rossi, F. Application of neutralising antibodies against NI-35/250 myelinassociated neurite growth inhibitory proteins to the adult rat cerebellum induces sprouting of uninjured Purkinje cell axons. J. Neurosci., 2000, 20, 2275-2286.

Buffo, A., Carulli, D., Rossi, F., Strata, P. Extrinsic regulation of injury/growth-related gene expression in the adult inferior olive. Eur. J. Neurosci., 2003, 18, 2146-2158.

Caroni, P., Aigner, L., Schneider, C. Intrinsic neuronal determinants locally regulate extrasynaptic and synaptic growth at the adult neuromuscular junction. J. Cell. Biol., 1997, 136, 679-692.

Carulli, D., Buffo, A., Strata, P. Reparative mechanisms in the cerebellar cortex. Prog. Neurobiol., 2004, 72, 373-398.

Chen, D.F., Jhaveri, S., Schneider, G.E. Intrinsic changes in developing retinal neurons result in regenerative failure of their axons. Proc. Natl. Acad. Sci. USA, 1995, 92, 7287-7291.

Chen, P., Goldberg, D.E., Kolb, B., Lanser, M., Benowitz, L.I. Inosine induces axonal rewiring and improves behavioral outcome after stroke. Proc. Natl. Acad. Sci. USA, 2002, 99, 9031-9036.

Chierzi, S., Ratto, G.M., Verma, P., FAwCETT, J.W. The ability of axons to regenerate their growth cones depends on axonal type and age, and is regulated by calcium, cAMP and ERK. Eur. J. Neurosci., 2005, 21, 2051-2062.

Condic, M.L. Adult neuronal regeneration induced by transgenic integrin expression. J. Neurosci., 2001, 21, 4782-4788.

Corvetti, L., Rossi, F. Degradation of chondroitin sulphate proteoglycans induces sprouting of intact Purkinje axons in the cerebellum of the adult rat. J. Neurosci., 2005, 25, 7150-7158.

DAVIES, A.M. Intrinsic programmes of growth and survival in developing vertebrate 
neurons. Trends Neurosci., 1994, 17, 195-199.

Davies, S.J.A., Fitch, M.T., Memberg, S.P., Hall, A.K., Raisman, G., Silver, J. Regeneration of adult axons in white matter tracts of the central nervous system. Nature, 1997, 390, 680-683.

Davies, S.J.A., Goucher, D.R., Doller, C., Silver, J. Robust regeneration of adult sensory axons in degenerating white matter of the adult rat spinal cord. J. Neurosci., 1999, 19, 5810-5822.

Doster, K.S., Lozano, A.M., Aguayo, A.J., Willard, M.B. Expression of the growthassociated protein GAP-43 in adult rat retinal ganglion cells following injury. Neuron, 1991, 6, 635-647.

Dusart, I., Airaksinen, M.S., Sotelo, C. Purkinje cell survival and axonal regeneration are age dependent: an in vitro study. J. Neurosci., 1997, 17, 37103726.

Dusart, I., Ghoumari, A., Wehrlé, R., Morel, M.P., Bouslama-Ougghlani, L., Camand, E., Sotelo, C. Cell death and axon regeneration of Purkinje cells after axotomy: Challenges of classical hypotheses of axon regeneration. Brain Res. Rev., 2005, 49, 300-316.

FAWCETT, J.W. Intrinsic control of regeneration and the loss of regenerative ability in development. In Axonal Regeneration in the Central Nervous System, Ingoglia, N.A., Murray, M. (Eds.), Marcel Dekker Inc., New York, Basel, 2001, pp. 219-266.

FAwCett, J.W., Asher, R.A. The glial scar and central nervous system repair. Brain Res. Bull., 1999, 49, 377-391.

Fawcett, J.W., Rosser, E., Dunnett, S.B. Brain Damage, Brain Repair. Oxford University Press, Oxford, 2001.

Fernandes, K.J., Kobayashi, N.R., Jasmin, B.J., Tetzlaff, W.G. Acetylcholinesterase gene expression in axotomised rat facial motoneurons is differentially regulated by neurotrophins: correlation with trkB and trkC mRNA levels and isoforms. J. Neurosci., 1998, 18, 9936-9947.

Fernandes, K.J., Fan, D.-P., Tsui, B.J., Cassar, S.L., Tetzlaff, W.G. Influence of the axotomy to cell body distance in rat rubrospinal and spinal motoneurons: different regulation of GAP-43, tubulins, and neurofilament-M. J. Comp. Neurol., 1999, 414, 495-510.

Fernandes, K.J., Tetzlaff, W.G. Gene expression in axotomized neurons: identifying intrinsic determinants of axonal growth. In Axonal Regeneration in the Central Nervous System, Ingoglia, N.A., Murray, M. (Eds.), Marcel Dekker Inc., New York, Basel, 2001, pp. 219-266.

Filbin, M.T. Myelin-associated inhibitors of axonal regeneration in the adult mammalian CNS. Nat. Rev. Neurosci., 2003, 4, 703-713.

Fischer, D., Pavlidis, M., Thanos, S. Cataractogenic lens injury prevents traumatic ganglion cell death and promotes axonal regeneration both in vivo and in culture. Invest. Ophthalmol. Vis. Sci., 2000, 41, 3943-3954.

Fischer, D., He, Z., Benowitz, L.I. Counteracting the Nogo receptor enhances optic nerve regeneration if retinal ganglion cells are in active growth state. J. Neurosci., 2004a, 24, 1646-1651.

Fischer, D., Petkova, V., Thanos, S., BENowitZ, L. Switching mature retinal ganglion cells to a mature growth state in vivo: gene expression and synergy with RhoA inactivation. J. Neurosci., 2004b, 24, 8726-8740.

Gianola, S., Rossi, F. Evolution of the Purkinje cell response to injury and regenerative potential during postnatal development of the rat cerebellum, J. Comp. Neurol., 2001, 430, 101-117.

Gianola, S., Rossi, F. GAP-43 overexpression in adult mouse Purkinje cells overrides myelin-derived inhibition of neurite growth. Eur. J. Neurosci., 2004, 19, 819-830.

Gianola, S., Savio, T., Schwab, M., Rossi, F. Cell-autonomous mechanisms and myelinassociated factors contribute to the development of Purkinje axon intracortical plexus in rat cerebellum. J. Neurosci., 2003, 23, 4613-4624.

Gold, B.G., КатоH, K., Storm-Dickerson, T. The immunosuppressant FK506 increases the rate of axonal regeneration in rat sciatic nerve. J. Neurosci., 1995, 15, 7509-7516.

Gold, B.G., Yew, J.Y., Zeleny-Pooley, M. The immunosuppressant FK506 increases GAP-43 mRNA levels in axotomized sensory neurons. Neurosci. Lett., 1998, 241, 25-28. 
Goldberg, J.L., Klassen, M.P., Hua, Y., BARres, B.A. Amacrine-signaled loss of intrinsic axon growth ability by retinal ganglion cells. Science, 2002, 296, 1860-1864.

HaAs, C.A., BaCh, A., Heimrich, B., Linke, R., Otten, U., Frotscher, M. Axotomyinduced c-Jun expression in young medial septal neurons is regulated by nerve growth factor. Neuroscience, 1998, 87, 831-844.

Hanz, S., Perlson, E., Willis, D., Zheng, J.-Q., Massarwa, R., Huerta, J.J., Koltzenburg, M., Kohler, M., vanMinnen, J., Twiss, J.L., Fainzilber, M. Axonal importins enable retrograde injury signalling in lesioned nerve. Neuron, 2003, 40, 1095-1104.

Hanz, S., Fainzilber, M. Integration of retrograde axonal and nuclear transport mechanisms in neurons: implications for therapeutics. Neuroscientist, 2004, 10, 404-408.

Harvey, P.J., Grochmal, J., Tetzlaff, W., Gordon, T., Bennett, D.J. An investigation into the potential for activity-dependent regeneration of the rubrospinal tract after spinal cord injury. Eur. J. Neurosci., 2005, 22, 3025-3035.

Hauben, E., Schwartz, M. Therapeutic vaccination for spinal cord injury: helping the body to cure itself. Trends Pharmacol. Sci., 2003, 24, 7-12.

Haug, H., Kölln, M., Rast, A. The postnatal development of myelinated nerve fibres in the visual cortex of the cat. Cell Tissue Res., 1976, 167, 265-288.

Herdegen, T., Brecht, S., Mayer, B., Leah, J., Kummer, W., Bravo, R., Zimmermann, M. Long-lasting expression of JUN and KROX transcription factors and nitric oxide synthase in intrinsic neurons of the brain following axotomy. J. Neurosci., 1993, 13, 4130-4145.

Herdegen, T., Skene, J.H.P., Bähr, M. The c-Jun transcription factor - bipotential mediator of neuronal death, survival and regeneration. Trends Neurosci., 1997, 20, 227-231.

Hiebert, G.W., Dyer, J.K., Tetzlaff, W., SteEVES, J.D. Immunological myelin disruption does not alter expression of regeneration-associated genes in intact or axotomized rubro-spinal neurons. Exp. Neurol., 2000, 163, 149-156.
Hofer, S.B., Mrsic-Flogel, T.D., Bonhoeffer, T., Hübener, M. Prior experience enhances plasticity in adult visual cortex. Nat. Neurosci., 2006, 9 , 127-132.

Hökfelt, T., Zhang, X., Wiesenfeld-Hallin, $Z$. Messenger plasticity in primary sensory neurons following axotomy and its functional implications. Trends Neurosci., 1994, 17, 22-30.

Hughes, P.E., Alexi, T., Hefti, F., Knusel, B. Axotomized septal cholinergic neurons rescued by nerve growth factor or neurotrophin-4/5 fail to express the inducible transcription factor c-Jun. Neuroscience, 1997, 78, 1037-1049.

HÜLL, M., B̈̈HR, M. Differential regulation of c-Jun expression in rat retinal ganglion cells after proximal and distal optic nerve transection. Neurosci. Lett., 1994, 178, 39-42.

KAPFHAMmer, J.P., SCHWAB, M.E. Inverse patterns of myelination and GAP-43 expression in the adult CNS: neurite growth inhibitors as regulators of neuronal plasticity? J. Comp. Neurol., 1994a, 340, 194-206.

KAPFHAMmer, J.P., Schwab, M.E. Increased expression of growth-associated protein GAP-43 in myelin-free rat spinal cord. Eur. J. Neurosci., 1994b, 6, 403-411.

Karimi-Abdolrezaee, S., Schreyer, D.J. Retrograde repression of Growth-Associated Protein-43 mRNA expression in rat cortical neurons. J. Neurosci., 2002, 22, 1816-1822.

Knudsen, E.I. Capacity for plasticity in the adult owl auditory system expanded by juvenile experience. Science, 1998, 279, 1531-1533.

Kobayashi, N.R., Fan, D.-P., Giehl, K.M. Bedard, A.M., Wiegand, S.J., Tetzlaff, W. BDNF and NT4/ 5 prevent atrophy of rat rubrospinal neurons after cervical axotomy, stimulate GAP-43 and T $\alpha 1$-tubulin mRNA expression, and promote axonal regeneration. J. Neurosci., 1997, 17, 9583-9595.

Kwon, B.K., Liu, J., Messerer, C., Kobayashi, N.R., McGraw, J., Oschipok, L., Tetzlaff, W.G. Survival and regeneration of rubrospinal neurons one year after spinal cord injury. Proc. Natl. Acad. Sci. USA, 2002, 99, 3246-3251.

Lander, C., Kind, P., Maleski, M., Hockfield, S. A family of activity- 
dependent neuronal cell surface chondroitin sulphate proteoglycans in the cat visual cortex. J. Neurosci., 1997, 17, 1928-1939.

Leah, J., Herdegen, T., Murashov, A., Dragunow, M., Bravo, R. Expression of immediate early gene proteins following axotomy and inhibition of axonal transport in the rat central nervous system. Neuroscience, 1993, 57, 53-66.

Leon, S., Yin, Y., Nguyen, J., Irwin, N., BENOwITZ, L.I. Lens injury stimulates axon regeneration in the mature rat optic nerve. J. Neurosci., 2000, 20, 4615-4626.

Li, D., Field, P.M., Raisman, G. Failure of axon regeneration in postnatal rat entorhino-hippocampal slice coculture is due to maturation of the axon, not that of the pathway or target. Eur. J. Neurosci., 1995, 7, 1164-1175.

Li, Y., Irwin, N., Yin, Y., LANSER, M., Benowitz, L.I. Axon regeneration in goldfish and rat retinal ganglion cells: differential responsiveness to carbohydrates and cAMP. J. Neurosci., 2003, 23, 7830-7838.

LIEBERMAN, A.R. The axon reaction: a review of the principal features of perikaryal response to axon injury. Int. Rev. Neurobiol., 1971, 24, 49-124.

LiU, R.-Y., SNider, W.D. Different signaling pathways mediate regenerative versus developmental sensory axon growth. J. Neurosci., 2001, 21, RC164.

Lorber, B., Berry, M., Logan, A. Lens injury stimulates adult mouse retinal ganglion cell axon regeneration via both macrophageand lens-derived factors. Eur. J. Neurosci., 2005, 21, 2029-2034.

Mandolesi, G., Madeddu, F., Bozzi, Y., Maffei, L., Ratto, G.M. Acute physiological response of mammalian central neurons to axotomy: ionic regulation and electrical activity. FASEB J., 2004, 18, 1934-1936.

Masden, J.R., MacDonald, P., Irwin, N., Goldberg, D.E., Yao, G.-L., Meiri, K.F., Rimm, I.J., Stieg, P.E., Benowitz, L.I. Tacrolimus (FK506) increases neuronal expression of GAP-43 and improves functional recovery after spinal cord injury in rats. Exp. Neurol., 1998, 154, 673-683.

Mason, M.R.J., Campbell, G., Caroni, P., Anderson, P.N., Lieberman, A.R. Overexpression of GAP-43 in thalamic projection neurons of transgenic mice does not enable them to regenerate axons through peripheral nerve grafts. Exp. Neurol., 2000, 165, 143-152.

Mason, M.R.J., Lieberman, A.R., Anderson, P.N. Corticospinal neurons upregulate a range of growth-associated genes following intracortical, but not spinal, axotomy. Eur. J. Neurosci., 2003, 18, 789-802.

McGee, A.W., Yang, Y., Fischer, Q.S., Daw, N.W., Strittmatter, S.M. Experiencedriven plasticity of visual cortex limited by myelin and Nogo receptor. Science, 2005, 309, 2222-2226.

Meyer, R.L., Miotke, J.A., Benowitz, L.I. Injury induced expression of growthassociated protein-43 in adult mouse retinal ganglion cells in vitro. Neuroscience, 1994, 63, 591-602.

Miyata, S., Akagi, A., Hayashi, N., Watanabe, K., Oohira, A. Activitydependent regulation of a chondroitin sulfate proteoglycan 6B4 phosphacan/RPTP beta in the hypothalamic supraoptic nucleus. Brain Res., 2004, 1017, 163-171.

Mohiuddin, L., Delcroix, J.D., Fernyhough, P., Tomlinson, R.D. Focally administered Nerve Growth Factor suppresses molecular regenerative responses of axotomized peripheral afferents in rats. Neuroscience, 1999, 91, 265-271.

Molteni, R., Zheng, Q.-J., Ying, Z., GomeZPinilla, F., Twiss, J.L. Voluntary exercise increases axonal regeneration from sensory neurons. Proc. Natl. Acad. Sci. USA, 2004, 101, 8473-8478.

Murray, M., Goldberger, M.E. Restitution of function and collateral sprouting in the cat spinal cord: the partially hemisected animal. J. Comp. Neurol., 1974, 158, 19-36.

Neumann, S., Woolf, C.J. Regeneration of dorsal column fibers into and beyond the lesion site following adult spinal cord injury. Neuron, 1999, 23, 83-91.

Neumann, S., Bradke, F., Tessier-Lavigne, M., Basbaum, A.I. Regeneration of sensory axons within the injured spinal cord induced by intraganglionic cAMP elevation. Neuron, 2002, 34, 885-893.

Neumann, S., Skinner, K., Basbaum, A.I. Sustaining intrinsic growth capacity of adult neurons promotes spinal cord regeneration. Proc. Natl. Acad. Sci. USA, 2005, 102, 16848-16852. 
Perlson, E., Hanz, S., Medzihradszky, K.F., Burlingame, A.L., Fainzilber, M. From snails to sciatic nerve: retrograde injury signaling from axon to soma in lesioned neurons. J. Neurobiol., 2004, 58, 287-294.

Perlson, E., Hanz, S., Ben-YaAkov, K., Segal-Ruder, Y., Seger, R., Fainzilber, M. Vimentin-dependent spatial translocation of an activated MAP kinase in injured nerve. Neuron, 2005, 45, 715-726.

Petrausch, B., Tabibiazar, R., Roser, T., Jing, Y., Goldman, D., Stuermer, C.A.O., IRwin. N., Benowitz, L.I. A purinesensitive pathway regulates multiple genes involved in axon regeneration in goldfish retinal ganglion cells. J. Neurosci., 2000, 20, 8031-8041.

Pfister, B.J., Iwata, A., Meaney, D.F., Smith, D.H. Extreme stretch growth of integrated axons. J. Neurosci., 2004, 24, 7978-7983.

Pizzorusso, T., Medini, P., Berardi, N., Chierzi, S., Fawcett, J.W., Maffei, L. Reactivation of ocular dominance plasticity in the adult visual cortex. Science, 2002, 298, 1187-1189.

Pons, T., Garraghty, P.E., Ommaya, A.K., KaAs, J.H., TAub, E., Mishrin, M. Massive cortical reorganization after sensory deafferentation in adult macaques. Science, 1991, 252, 1857-1860.

Purves, D., Lichtman, J. Principles of Neural Development. Sinauer Ass., Sunderland, 1985.

Purves, D., Voyvodic, J.T., Magrassi, L., YAwo, H. Nerve terminal remodelling visualized in living mice by repeated examination of the same neuron. Science, 1987, 238, 1122-1126.

Qiu, J., Cai, D., Dai, H., McAtee, M., Hoffman, P., Bregman, B.S., Filbin, M.T. Spinal axon regeneration induced by elevation of cyclic AMP. Neuron, 2002, 34, 895-903.

Raineteau, O., Schwab, M.E. Plasticity of motor systems after incomplete spinal cord injury. Nat. Rev. Neurosci., 2001, 2, 163-273.

RaIsman, G. Myelin inhibitors: does NO mean GO? Nat. Rev. Neurosci., 2004, 5, 157-161.

Raisman, G., Field, P.M. A quantitative investigation of the development of collateral reinnervation after partial deafferentation of the septal nuclei. Brain Res., 1973, 50, 241-264.
Richardson, P.M., Issa, V.M.K. Peripheral injury enhances central regeneration of primary sensory neurones. Nature, 1984, 309, 791-793.

Rossi, F. Regulation of the intrinsic growth properties in mammalian neurons. In Brain Damage and Repair. From Molecular Research to Clinical Therapy. Delgado-Garcia, J.M., Herdegen, T. (Eds.), Kluwer Academic Publishers. Amsterdam, 2004, pp. 349-363.

Rossi, F., Wiklund, L., VAN DER WANT, J.J.L., Strata, P. Reinnervation of cerebellar Purkinje cells by climbing fibres surviving a subtotal lesion of the inferior olive. I. Development of new collateral branches and terminal plexuses. J. Comp. Neurol., 1991, 308, 513-535.

Rossi, F., Jankovski, A., Sotelo, C. Differential regenerative response of Purkinje cell and inferior olivary axons confronted with embryonic grafts: environmental cues versus intrinsic neuronal determinants. J. Comp. Neurol., 1995, 359, 663-677.

Rossi, F., Saggiorato, C., Strata, P. Targetspecific innervation of embryonic cerebellar transplants by regenerating olivocerebellar axons in the adult rat. Exp. Neurol., 2002, 173, 205-212.

Sauvé, Y., Sawai, H., Rasminsky, M. Topological specificity in reinnervation of the superior colliculus by regenerated retinal ganglion cell axons in adult hamsters. J. Neurosci., 2001, 21, 951-960.

Schaden, H., Stürmer, C.A.O., B̈̈Hr, M. GAP-43 immunoreactivity and axon regeneration in retinal ganglion cells of the rat. J. Neurobiol., 1994, 25, 1570-1578.

Schoop, V.M., Gardziella, S., Müller, C.M. Critical period-dependent reduction of the permissiveness of cat visual cortex tissue for neuronal adhesion and neurite growth. Eur. J. Neurosci., 1997, 9, 1911-1922.

Schreyer, D.J., Skene, J.H.P. Fate of GAP-43 in ascending spinal axons of DRG neurons after peripheral nerve injury: delayed accumulation and correlation with regenerative potential. J. Neurosci., 1991, 11, 3738-3751.

Schreyer, D.J., Skene, J.H.P. Injuryassociated induction of GAP-43 expression displays axon branch specificity in rat dorsal root ganglion neurons. J. Neurobiol., 1993, 24, 959-970. 
Schwab, J.A., Failli, V., ChÉdotal, A. Injuryrelated dynamic myelin/oligodendrocyte axon-outgrowth inhibition in the central nervous system. Lancet, 2005, 365, 255257.

Schwab, M.E. Nogo and axon regeneration. Curr. Opin. Neurobiol., 2004, 14, 118-124.

Schwab, M.E., Schnell, L. Channeling of developing corticospinal tract axons by myelin-associated neurite growth inhibitors. J. Neurosci., 1991, 11, 709-721.

Schwab, M.E., Kapfhammer, J.P., Bandtlow, C.E. Inhibitors of neurite growth. Annu. Rev. Neurosci., 1993, 16, 565-595.

Schwartz, M. Optic nerve crush: protection and regeneration. Brain Res. Bull., 2004, 62, 467-471.

Shadiack, A.M., Vaccariello, S.A., Sun, Y., ZIGMOND, R.E. Nerve growth factor inhibits sympathetic neurons' response to an injury cytokine. Proc. Natl. Acad. Sci. USA, 1998, 95, 7727-7730.

Silver, J., Miller, J.H. Regeneration beyond the glial scar. Nat. Rev. Neurosci., 2004, 5, 146-156.

Skene, J.H.P. Axonal growth-associated proteins. Annu. Rev. Neurosci., 1989, 12, 127-156.

SKENE, J.H.P. Retrograde pathways controlling expression of major growth cone components in the adult CNS. In The Nerve Growth Cone. Letourneau, P.C., Kater, S.B., Macagno, E.R. (Eds.), Raven Press, New York, 1992, pp 463-475.

Smith, D.S., Skene, J.H.P. A transcriptiondependent switch controls competence of adult neurons for distinct modes of axon growth. J. Neurosci., 1997, 15, 646-658.

Tetzlaff, W.G., Kobayashi, N.R., Giehl, K.M.G., Tsui, B.J., Cassar, S.L., Bedard, A.M. Response of rubrospinal and corticospinal neurons to injury and neurotrophins. In Neural Regeneration. Prog Brain Res., Vol. 103, SEIL F.J. (Ed.), Amsterdam: Elsevier, 1994, pp. 271-286.

Thallmair, M., Metz, G.A.S., Z'Graggen, W.J., Raineteau, O., Kartje, G.L., Schwab, M.E. Neurite growth inhibitors restrict plasticity and functional recovery following corticospinal tract lesions. Nat. Neurosci., 1998, 1, 124-131.

Thanos, S., Naskar, R., Heiduschka, P. Regeneration of ganglion cell axons in the adult rat establishes retinofugal topography and restores visual function. Exp. Brain

Res., 1997, 11, 483-491.

Udvadia, A.J., Köster, R.W., Skene, J.H.P. GAP-43 promoter elements in transgenic zebrafish reveal a difference in signals for axon growth during CNS development and regeneration. Development, 2001, 128, 1175-1182.

Vaudano, E., Campbell, G., Anderson, P.N., Davies, A.P., Woolhead, C., Schreyer, D.J., Lieberman, A.R. The effects of a lesion or a peripheral nerve graft on GAP43 upregulation in the adult brain: an in situ hybridisation and immunocytochemical study. J. Neurosci., 1995, 15 , 3594-3611.

Verma, P., Chierzi, S., Codd, A.M., Campbell, D.S., Meyer, R.L., Holt, C.E., FAWCETT, J.W. Axonal protein synthesis and degradation are necessary for efficient growth cone regeneration. J. Neurosci., 2005, 25, 331-342.

Verzì, L., Buffo, A., Rossi, F., Ofestreicher, A.B., Gispen, W.H., Strata, P. Increase in GAP-43 immunoreactivity in uninjured muscle nerves of the mdx mice. Neuroscience, 1996, 70, 807-815.

Woolf, C.J., Molander, C., Reynolds, M., BENOwITZ, L.I. GAP-43 appears in the rat dorsal horn following peripheral nerve injury. Neuroscience, 1990, 34, 465-478.

Wu, W., Mathew, T.C., Miller, F.D. Evidence that the loss of homeostatic signals induces regeneration-associated alterations in neuronal gene expression, Dev. Biol., 1993, 158, 456-466.

Yin, Y., Cui, Q., Li, Y., Irwin, N., Fischer, D., Harvey, A.R., Benowitz, L.I.

Macrophage-derived factors stimulate optic nerve regeneration. J. Neurosci., 2003, 23, 2284-2293.

Zagrebelsky, M., Rossi, F., Hawkes, R., STRATA, P. Topographically arranged climbing fibre sprouting in the adult rat cerebellum. Eur. J. Neurosci., 1996, 8, 1051-1054.

Zagrebelsky, M., Strata, P., Hawkes. R., Rossi, F. Reestablishment of the olivocerebellar projection map by compensatory transcommissural reinnervation following unilateral transection of the inferior cerebellar peduncle in the newborn rat. J. Comp. Neurol., 1997, 379, 283-299. 
Zagrebelsky, M., Buffo, A., Skerra, A., Schwab, M.E., Strata, P., Rossi, F. Retrograde regulation of growth-associated gene expression in adult rat Purkinje cells by myelin-associated neurite growth inhibitory proteins. J. Neurosci., 1998, 18, 7912-7929.

Z'Graggen, W.J., Metz, G.A.S., Kartje, G.L., Thallmair, M., Schwab, M.E. Functional recovery and enhanced corticofugal plasticity after unilateral pyramidal tract lesion and blockade of myelin-associated neurite growth inhibitors in adult rats. J. Neurosci., 1998, 18, 4744-4757.

Zhang, Y., Bo, X., Schoepfer, R., HoltmaAt, A.J.D.G., VerhaAgen, J., Emson. P.C., Lieberman, A.R., Anderson, P.N. Growthassociated protein GAP-43 and L1 act synergistically to promote regenerative growth of Purkinje cell axons in vivo. Proc. Natl. Acad. Sci. USA, 2005, 41, 14883-14888. 